\title{
Exploring mechanisms for systemic thinking in decision-making through three country applications of SDG Synergies
}

\author{
Karina Barquet ${ }^{1}(1) \cdot$ Linn Järnberg $^{1} \cdot$ Ivonne Lobos Alva $^{2} \cdot$ Nina Weitz $^{1}$
}

Received: 4 January 2021 / Accepted: 14 September 2021 / Published online: 5 October 2021

(c) The Author(s) 2021

\begin{abstract}
Increased systems thinking capacity - that is, the capacity to consider systemic effects of policies and actions-is necessary for translating knowledge on Sustainable Development Goals' (SDGs) interactions into practice. Various models and tools that seek to support more evidence-based policy-making have been developed with the purpose of exploring system effects across SDGs. However, these often lack integration of behavioral aspects and contextual factors that influence the decision-making process. We analyze three applications of a decision-support approach called SDG Synergies, which aims at building capacity in systems thinking among decision-makers and implementing agencies. Our objective is to explore how behavior and context influences whether and how knowledge is taken up and acted upon when making decisions. Drawing on empirical material from Mongolia, Colombia, and Sri Lanka, we identify three sets of mechanisms that appear important for enabling more systemic thinking: system boundaries (time, scale, and space), rules of engagement (ownership, representation, and purpose), and biases (confirmation biases and participation biases). Results highlight some key challenges for systemic thinking that merit further attention in future applications, including the importance of localizing SDGs and incorporating this knowledge to national-level assessments, an unwillingness of stakeholders to acknowledge trade-offs, the challenge of addressing transformational as opposed to incremental change, and striking a balance between the flexibility of the approach vis-à-vis scientific robustness.
\end{abstract}

Keywords Decision-making $\cdot$ Knowledge uptake $\cdot$ Capacity building $\cdot$ Behavioral theory $\cdot$ Sustainable governance

\section{Introduction}

The indivisible nature of Agenda 2030 places demands on understanding — and acting upon-synergies and trade-offs that emerge in implementation of diverse policy goals (Nilsson et al. 2018). In response to this, the scientific community is putting forward different approaches to analyze and account for interactions among the 17 SDGs and promote

Handledby Fabrice Renaud, University of Glasgow, United Kingdom.

Karina Barquet

karina.barquet@sei.org

1 Stockholm Environment Institute, Linnégatan 87D, 10451 Stockholm, Sweden

2 Stockholm Environment Institute, Latin America Center, Calle 71, \#11-10, Edificio Corecol Oficina 801, Bogotá, Colombia that more systemic thinking guides decisions (Bennich et al. 2020). Many of these approaches rely on linear approaches and rational theories (Barbier and Burgess 2019; Lusseau and Mancini 2019) despite their limitations to address issues like SDG implementation, characterized by high uncertainty and applied under contexts with imperfect and insufficient data (Nilsson et al. 2017). Under such contexts, it cannot be assumed that more or improved quality of data will translate into more rational decision-making (Bell et al. 1999; Schlüter et al. 2017). Besides lack of data, policymakers are faced with implementing the SDGs in political realities with many competing interests and in processes which are deeply embedded in contextual and behavioral aspects (Ajzen 1991), such as interest in maintaining the status quo and risk aversion (Weber 2017). Despite this, there continues to be a remarkable lack of integration of behavioral and contextual mechanisms in tools and decision-support models for the implementation of the SDGs. 
The trust put on linear and rational theory approaches for inducing policy change poorly reflects empirical knowledge on human decision-making, and the uncertainties surrounding decision-making on issues that are largely influenced by other complex mechanisms (Schlüter et al. 2017). Though behavioral economists have long highlighted the inadequacy of rational theories in contexts of complex decision-making (Kahneman and Tversky 1979; Vieider and Vis 2019), we see a recent interest in tools and models that can integrate context and behavior into decision-support tools for sustainability (Sarkki et al. 2014; Cvitanovic et al. 2016; Gavine et al. 2018; Moallemi et al. 2020). This paper is a contribution to these calls. It speaks to the challenge that many decision-support models are built on a strong trust in the power of evidence to induce policy change, though this assumption poorly reflects empirical knowledge on what determines decision-making.

The literature on decision-making highlights the importance of knowledge (Jasanoff 2010; Berg and Lidskog 2018) and capacity building (Parsons 2004) as two key avenues for systemic thinking. It calls for stronger integration of behavioral and contextual aspects to define whether and how evidence translates into knowledge, and how knowledge permeates decision-making processes. As for systemic thinking in decision-making, theory points in particular to the importance of knowledge uptake and capacity building (Cash et al. 2003; Parsons 2004; Jasanoff 2010, 2012).

However, the mechanisms that trigger learning and capacity building in the first place, and how such mechanisms play out in contexts characterized by uncertainty and complexity, are not equally documented. The aim of this paper is to identify such mechanisms and explore how they work to promote systemic thinking for SDG implementation. The question we explore is, what determines knowledge uptake and capacity building in real-world decision-making processes and how can knowledge uptake and capacity building support more systemic thinking? We do this by analyzing three country applications of a decision-support approach that is suited to inform policy formulation for SDG implementation called SDG Synergies. SDG Synergies is based on systems analysis and aims at providing actionable and integrated knowledge and to build capacity in systems thinking among decisionmakers and implementing actors (Weitz et al. 2018).

The paper is organized as follows. The next section introduces the theory background. An overview of the methodological approach including the steps followed in the country applications is presented in "Methods". Building on these sections, "Results" presents the three country applications in relation to eight identified mechanisms for promoting knowledge uptake and capacity building for systems thinking in SDG implementation. The last section presents a discussion and concluding remarks, including key challenges that need to be addressed in future applications.

\section{Theory}

Research in knowledge co-production sheds light on critical aspects for generating high-quality, actionable knowledge. Knowledge co-production is understood as the collaborative process of bringing a plurality of knowledge sources and types together to address a defined problem and build an integrated or systems-oriented understanding of that problem (Armitage et al. 2011). Cash and colleagues (2003) have identified a group of principles to increase the uptake and use of co-produced knowledge. These principles consider how authoritative, believable, and trusted information is (credibility); how "fair" the process of producing information is and whether it considers values, concerns, and perspectives of different actors (legitimacy); and how relevant the information is to decision-making bodies or audiences (salience).

As for building capacity for systems thinking, we refer to improving the ability of governments to understand and manage complex realities and steer strategically. According to Parsons (2004), capacity building involves at least two things: one is about increasing decision-makers' ability to map and navigate the complexities of interconnected problems, multi-level governance, multi-organizational settings, cross-cutting issues, policy networks, inter-dependencies, and linkages; second is about the ability to integrate competing and opposing forms of knowledge and coordinating the multiplicity of organizations and interests to form a coherent policy fabric.

We specifically focus on exploring three sets of mechanisms of particular relevance for deliberative processes (Dryzek 2001; Van Lieshout et al. 2017): system boundaries, which determine the conditions that will be used to frame and execute the decision-making process (Cash et al. 2003); rules of engagement, which concern mechanisms related to the process of deliberation (Boyko et al. 2012); and biases, understood as any deviation in decision-making from the standard framework of rational choice (Engler et al. 2019). These mechanisms should not be seen as exhaustive, and it is important to highlight that the diverse body of literature considers contextual and behavioral aspects in often overlapping but slightly different ways. ${ }^{1}$ As illustrated in Fig. 1, we assume that addressing and integrating these mechanisms into decision-making processes contribute to knowledge uptake as well as increased systems thinking capacity.

\footnotetext{
$\overline{1}$ see Schlüter et al., 2017 for a comprehensive discussion on behavioral theory.
} 
Fig. 1 Mechanisms to foster knowledge uptake and capacity building for systemic thinking in decision-making

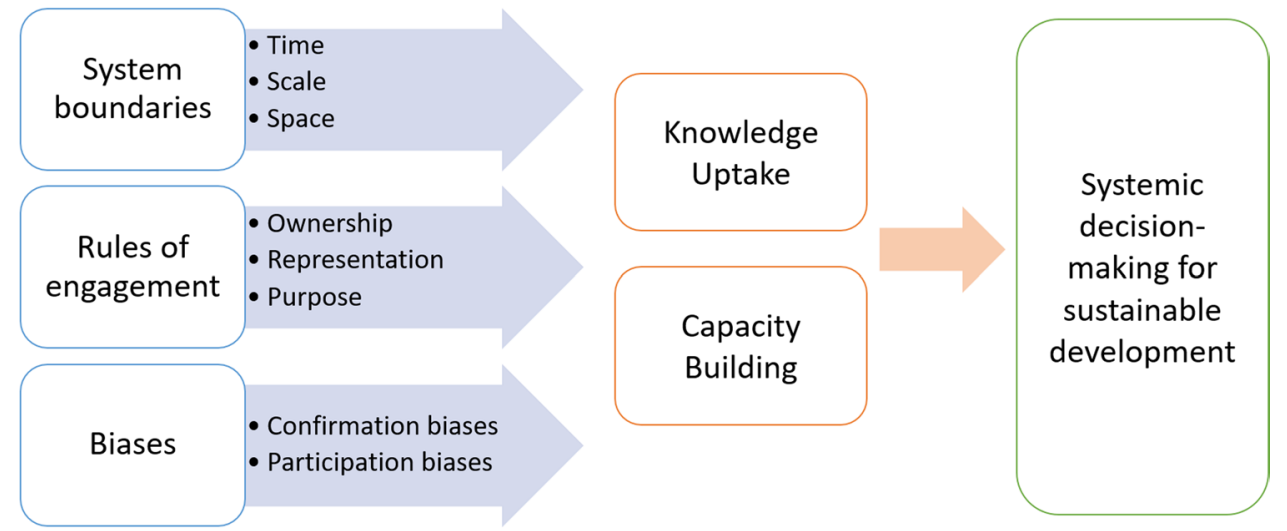

\section{System boundaries}

System boundaries concern mechanisms related to the context in which the engagement process is embedded. We identify three mechanisms: time, scale, and space.

Our understanding of time has direct impacts for how we imagine the relationship between different constructs (George and Jones 2000), and this in turn limits how we imagine the future should be governed (Butler 1995). Because of this, our understanding of time lies at the heart of imagining transformative as opposed to incremental change.

Scale is defined as the representation of any area as produced and defined by social processes (Lefebvre 1991). These constructs have real political implications (Latour 1983) by shaping the meaning of policy issues, with potential implications for governance processes in terms of responsibilities and inclusion or exclusion of actors and ideas (Van Lieshout et al. 2017). Considering scale in decision-making is important to reflect upon how the process in question needs to be unpacked, the social and economic processes called for when doing it, and the political consequences from selecting a scale of action.

While in geographic terms, space is always political, the space of policy, which we refer to in this paper, is the room where political commitment and policy direction are settled, given the conditions of scale and time (Massey 2005). Policy is made and executed not only within jurisdictional spaces, but is increasingly socially co-constituted across dynamized institutional landscapes (Peck 2011). Part of anchoring decision-making within a space is to determine the political and financial setup which are important starting points for the process; whether there are prescribed policy mechanisms that the decision-making will contribute to; and whether real budget lines or development priorities can be used to align its purpose.

\section{Rules of engagement}

Ownership, representation, and purpose are crucial for creating the conditions for participation, and ensuring that these elements are in place requires careful facilitation to bridge diverse perspectives (Chambers et al. 2021). A key challenge lies in creating decision spaces that give voice to a broad range of actors, while ensuring that participation is also representative of society and aligned to the purpose of the process (Bennich et al. 2020).

Ownership is sometimes defined as the responsibility, obligation, and caring imbued by individuals in problem situations (Wondolleck and Yaffee 2000). Lachapelle and McCool (2005) expand this definition to include three characteristics: ownership in process (whose voice is heard), ownership in outcome (whose voice is codified), and the ownership distribution (who is affected by the action). In decision-making processes of public concern that are facilitated by third parties, obtaining commitment from the actors owning the process, the outcome, and the distribution is key for obtaining engagement and commitment.

When it comes to representation, the issue of who should be involved in a process puts into question the very concept of participation and the legitimacy of decision-making. The act of inclusion also implies exclusion, which can lead to decisions often appearing to be illegitimate for those that have been left out. At the same time, expanding participation widely can reduce the potential of meaningful deliberation (Parkinson 2003). Both Dryzek (2001) and Parkinson (2003) suggest detaching the idea of legitimacy from a mere head count of individuals, and instead conferring legitimacy by representation. For this, it becomes crucial to "find rules that legitimately exclude, rather than making legitimacy depend, impossibly, on full inclusion" (Parkinson 2003, p. 188). The rules for representation are highly contextual and intimately linked to questions of ownership (Ney and Verweij 2014). 
The purpose of the intervention defines what is at stake and how the process will be designed to achieve the purpose. Is the purpose to improve the quality of the decision output (a functionalist approach)?; to represent all values and preferences in proportion to their share in the affected population (the neoliberal approach)?; to debate the criteria of truth, normative validity and truthfulness (the deliberative approach)?; or to demonstrate variability, plurality and legitimacy of opposing views (the postmodern approach)? (Renn and Schweizer 2009).

\section{Biases}

It is important to understand how different policy options are evaluated and justified as rational, by an individual or a group, even if they may not be objectively optimal. Individuals within a group may share similar understandings of alternatives and this mutual understanding is what allows them to operate jointly, irrespective of facts and data. Rationality in this case is not about correct (factual) decision-making but about aligning perceptions to the context and group to create a common understanding. To an external observer, the decisions taken might appear as irrational, but for the individuals in the group, perceptions driving decisions share cognitive bounds and contextual references (Halpern and Stern 2018). These are reinforced by biases, in particular confirmation biases and participation biases.

Socially contextualized confirmation biases refer to when individuals seek, remember, and prefer information in a manner that confirms prior views (Banuri et al. 2019). The work by Banuri and colleagues highlights how technical expertise does not by itself resolve the problem of ideologically motivated or socially influenced confirmation bias. While deliberation within diverse groups can reduce confirmation biases, when people reason with like-minded peers, confirmation biases lead them to reinforce their initial attitudes (Mercier and Landemore 2012).

Participation refers to how people engage and exchange knowledge in collective processes, which is influenced by a range of contextual factors that define the outcomes of engagement (Reed et al. 2018). A type of participation bias is hierarchies. Deliberative democratic theorists recognize the importance of equality as a precondition for effective deliberation. Yet, the gap between the equality presumed to be theoretically necessary for effective deliberation and the equality present in practice may be wider than initially perceived (Pierce et al. 2008). This is particularly the case in hierarchical organizations. Differences in status and the inequalities of power that flow from these differences may be necessary for the organization to function, yet they pose real challenges for the process of deliberation. The inequalities of power that hierarchies naturally produce affect group dynamics that in turn may lead to high-status individuals participating more than low-status ones (Caza et al. 2011). Other power inequalities include those produced by gender and social equity embedded in societies, impacting the ways in which individuals interact and communicate, but also determining whose voice gets heard the most.

\section{Methods}

This section provides an overview of the approach for addressing research question, as well as the steps used to operationalize the SDG Synergies Approach.

\section{Learning by doing}

We adopt a 'learning by doing' approach whereby policymaking setups are used as experiments for enabling stakeholders to learn by doing (Holling 1978). Learning by doing is facilitated by treating uncertainties not as obstacles to overcome but opportunities to learn from, and by including feedback loops that enhance understanding of the process (Kato and Ahern 2008).

The empirical material presented in this article was obtained through direct observations and documentation of the processes in each of the countries. The authors have been directly involved in the applications by designing and facilitating the process in close dialog with the respective governments and other actors. This has been complemented by surveys with workshop participants in Colombia (130 responses) and Mongolia (25 responses), and a follow-up informal interview of $1 \mathrm{~h}$ with a key government representative in Mongolia. Informants granted permission to use the information gathered for scientific purposes.

Literature on knowledge uptake and capacity building provided us with entry points for designing the analysis of the country applications. Observations from the three applications then complemented these initial ideas. Based on observations and the initial benchmarking of relevant literature, we expanded the search through a snowball approach for identifying relevant sources. An important starting point was the paper by Schlüter and colleagues (2017). Following this exercise, we arrived at the set of refined mechanisms, presented in the theory section, that emerged as important for knowledge uptake and capacity building in promoting more systemic thinking. Through observations from the three country applications of SDG Synergies, we reflect upon the mechanisms and how they play out in real processes of complex decision-making. The three country applications represent three different processes with different 


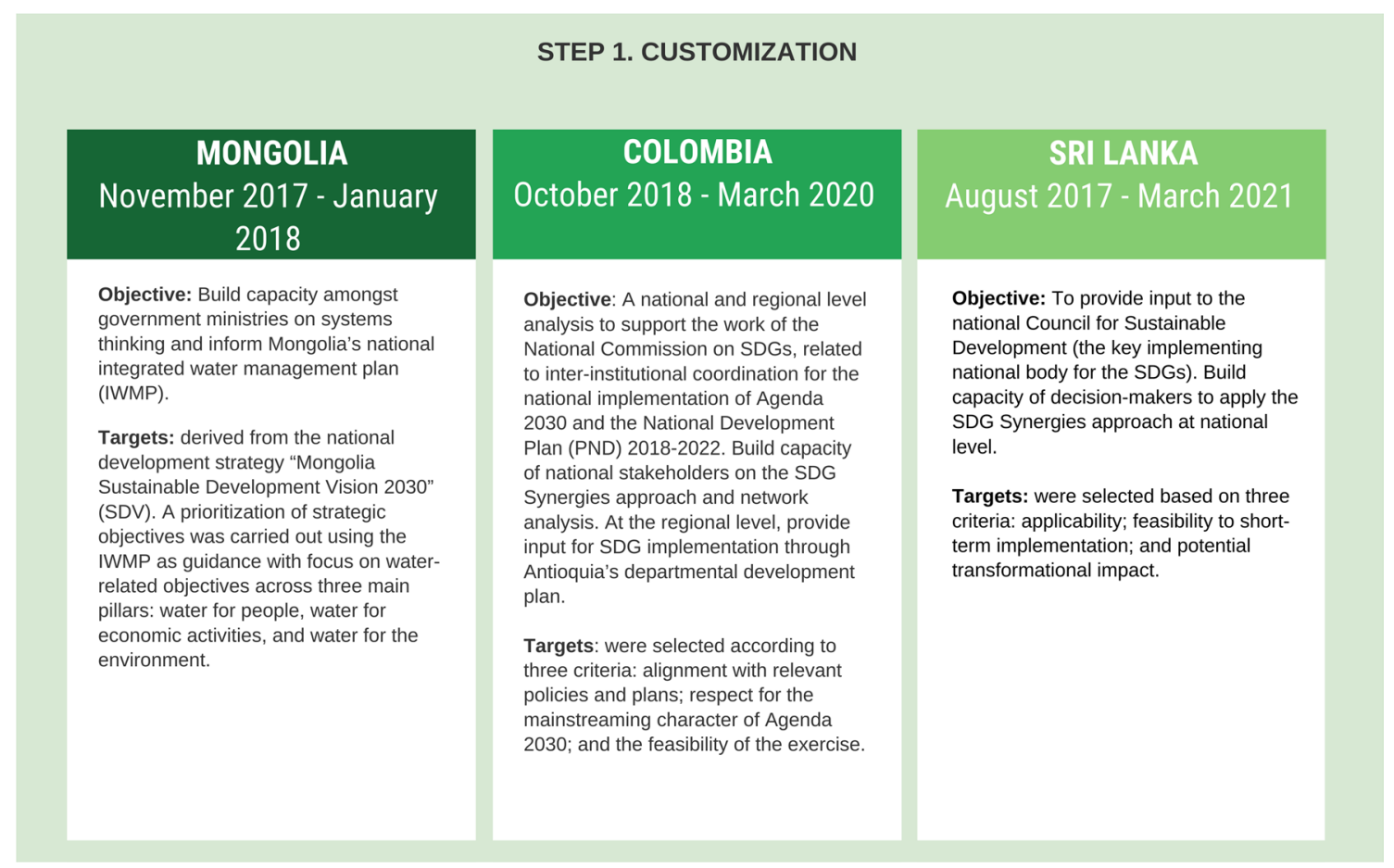

Fig. 2 Descriptive table of customization of SDG Synergies application in Mongolia, Colombia, and Sri Lanka

conditions for knowledge uptake and capacity building as described in more detail below.

\section{Three applications of SDG Synergies}

SDG Synergies is an approach to support decision-making that attempts to shift away from one-way sectoral discussions toward a more systemic approach to decision-making. A key element is that it provides a simple framework for systematically considering both synergies-or positive systemic impacts (represented by + values on the scale in Fig. 5A) and trade-offs-or negative systemic impacts (represented by - values on the scale in Fig. 5A) among a large set of goals, in a way that stimulates cross-sectoral thinking and engagement of relevant stakeholders. While this discussion-based input is meant to facilitate learning, build ownership, and trust it also provides the basis for a systems analysis (network analysis) that shows how progress on one goal influences other parts of Agenda 2030. Results from SDG Synergies can inform decisions on SDG implementation with regards to, e.g., prioritization based on the systemic impact of progressing on the different goals, identification of policy interventions that generate most support across the whole Agenda, manage potential clashes between goals and capture synergies, and create cross-sectoral partnerships that are aligned with how goals interact (Weitz et al. 2018).
The operationalization of SDG Synergies is carried out through three steps: (1) customization in terms of context and scope; (2) an interactions assessment based on systematic qualitative cross-impact analysis facilitated by crosssectoral dialogues; (3) and analysis including a network analysis.

\section{Step 1: Customization}

The first step consists of customizing the process to the specific context in which it will be applied, e.g., a region, country, subnational level, by policies and plans in place or under development and the key questions in focus. Customization entails defining the objective (purpose and scope), identifying the stakeholders and their role, selecting SDG targets to be included in the analysis, and thereafter designing the application (e.g., workshops). Customization often requires several iterations between the different parties involved.

Figure 2 presents the defining characteristics of the first step in each case and allows for an overview of similarities and differences.

In all three cases, the process was owned by the main national agencies appointed to oversee the implementation of Agenda 2030. SEI's role in all three cases was of a knowledge broker and facilitator, who provided a scientifically grounded method. Two of the workshops (Mongolia and the regional workshop in Colombia) focused on integrated water governance. 


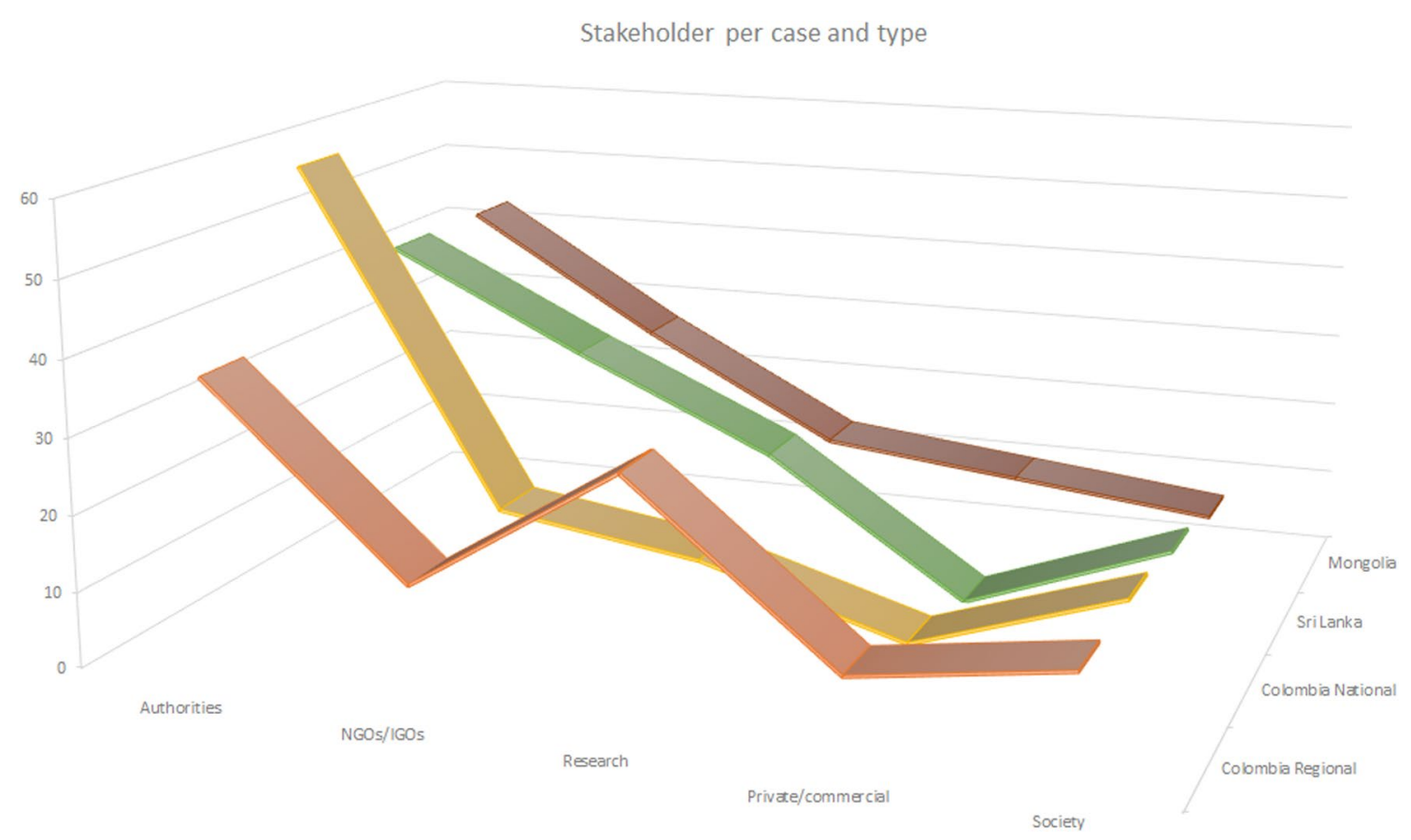

Fig. 3 Distribution of participants in the different cases (presented in percentages)

In Mongolia, the application of SDG Synergies used as starting point the national development goals that the government had previously harmonized with Agenda 2030. The exercise was primarily steered toward capacity building on systems thinking and to pilot-test a process that could improve policy coherence in cross-sectoral policy planning. The main targets were water-related, while in the selection of the non-water sector targets, the following guiding principles were considered: national context, importance to the national economy, importance for livelihoods and social welfare, and importance for ecosystem services. Priority was given to targets with more direct linkages to water. Considerations were also made to ensure that the selection of targets is aligned with the distribution of objectives in the SDV across the four groups (economic, social, environmental, and governance). The initial selection of targets was carried out by SEI within the policies outlined by the National Designated Authority (NDA). This selection was reviewed by NDA and adjusted thereafter.

In Colombia, the workshops were framed according to the timeline of the National Development Plan, as well as with the current government mandate (2018-2022). Together with the National Planning Department and the Ministry of Environment and Sustainable Development, 20 SDG targets were prioritized for the national workshop. For the regional workshop, 15 SDG targets were prioritized and selected together with local partners. Results informed the work of the National Commission on SDGs, particularly in terms of inter-institutional coordination for the national implementation of Agenda 2030. At the regional level, it served as input into the process of implementing SDGs in Antioquia and informed the new departmental development plan, where water management was a central aspect.

The process in Sri Lanka was more closely tied to policy making and was, as a result, longer and involved more consultations and iterations. The Ministry of Sustainable Development assigned an Expert Committee with cross-ministerial and sectoral representation to undertake the selection of SDG targets. Experts individually ranked each of the 169 SDG targets based on the three criteria, and based on this, a shortlist of 36 covering all 17 SDGs was produced.

As part of the customization step in all three countries, background materials and guidance documents were prepared with information on the SDGs and their targets, on national policies and plans related to the SDGs, as well as with national indicators and other commitments. This was important to allow participants to engage in the assessments with the same (or similar) level of information. The material was later used to support the scoring of interactions. This material also helped to increase awareness and knowledge of the SDGs and their targets.

In all cases, government partners together with UN Agency representatives were responsible for the selection of participants. However, this selection was guided by certain criteria: the interventions primarily targeted decision-makers but aimed also to obtain sectoral balance, representation from the private and civil society spheres, and inclusion of 
STEP 2. INTERACTIONS ASSESSMENT

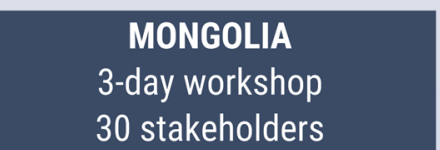

The assessment was carried out using a scoring matrix with 272 interactions $(17 * 17$ targets) in three steps using different group constellations:

1) Matrix 1 had 4 * 4 interactions. For the first two interactions, scoring was carried out in plenary for training purposs and the value assigned was through consensus.

2) The second two interactions in matrix 1 , were scored in pairs. Facilitators rotated amongst the tables.

3) Groups of three to five persons were formed. Each group was assigned a matrix. The groups assigned one value per interaction. Consensus was encouraged, but whenever consensus could not be reached participants averaged their individual scores. For each scored pair, participants wrote a justification to understand the logic of the scores and validate the results.

\section{COLOMBIA \\ Two 2-day workshops 160 stakeholders}

The national workshop was attended by 100 experts, and the regional workshop was attended by 60 experts.

Both workshops included the scoring of the interactions using the SDG Synergies web-based tool. Matrices were filled through group discussions (of 5-6 participants) but each participant entered one score, which was then averaged in the group. Participants could indicate uncertainty in their score, which would allow discussion of those scores in plenary. Participants provided justifications for their scores. Each working group scored a section of the matrix and at the end, the full matrix was discussed in plenary.

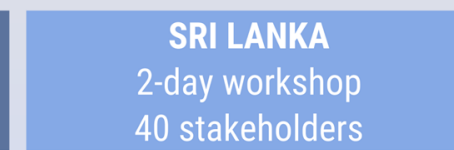

For training purposes, the first interactions were scored in groups of six, supported by a facilitator. The subsequent scoring was done in pairs using the SDG Synergies web-based tool. Each pair scored the impacts from progress on two SDG targets, corresponding to their sectoral expertise.

Stakeholders were encouraged to reach consensus, and only one score per interaction was recorded. In case of disagreement, the interaction was discussed in a larger group of six participants. They were encouraged to enter a qualitative justification of their score. Scores were verified by a different pair of participants, and in case of disagreement between the original scorers and the verifiers, scores were again

brought up for discussion within a group of six participants.

Fig. 4 Descriptive table of Interactions Assessment of SDG Synergies in Mongolia, Colombia, and Sri Lanka

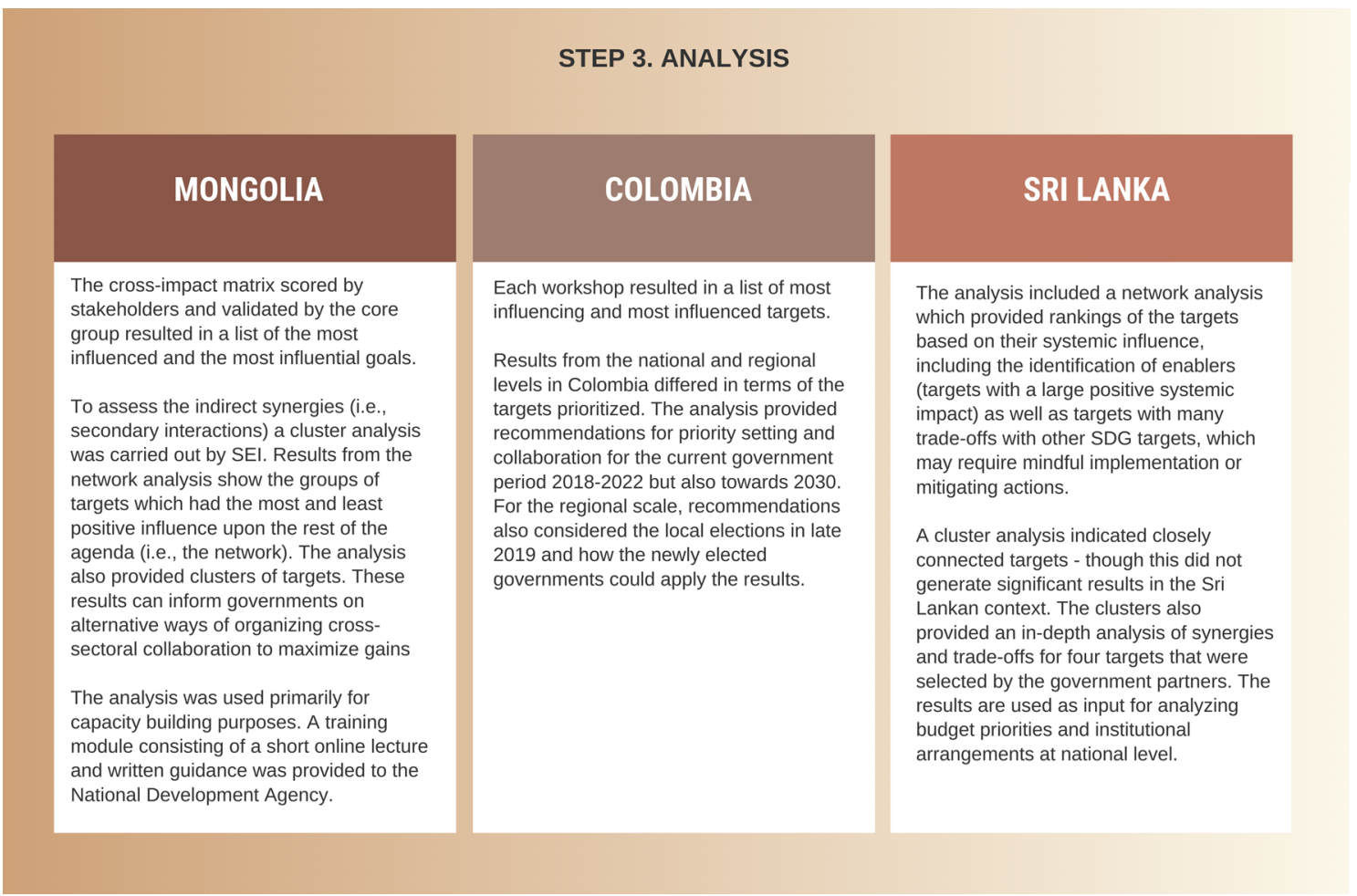

Fig. 5 Descriptive table of Analysis of SDG Synergies in Mongolia, Colombia, and Sri Lanka 
different social groups. The selection also aimed at a mix of high-level and technical staff, as well as gender balance. Figure 3 shows estimated numbers for each of the countries and according to five main stakeholder groups. However, stakeholder participation fluctuated, particularly in the case of Sri Lanka which had a longer term engagement (Fig. 4).

All country applications were designed to be executed through a participatory approach intended to a) ensure an appropriate agenda that aimed at creating equal opportunities for participation; b) the right group size that would enable rich discussions and a variety of opinions without crowding out the space for interaction; c) leadership and moderation to guide the interaction among actors and their involvement; and d) ground rules set at the onset to help overcome feelings of uncertainty about how to proceed in a multi-actor environment.

\section{Step 2: Interactions assessment}

In the second step, stakeholders assess the direct interactions between all the selected goals/targets (Fig. 4).

Stakeholders score systematically, working with two goals/targets at a time, and feeding scores into a crossimpact matrix. In Mongolia, this was done using an early (excel) version of the cross-impact matrix. This early version was later developed into the online SDG Synergies tool which was used in Colombia and Sri Lanka. ${ }^{2}$ Each interaction is assigned a score defining the strength of the interaction going from strongly restricting to strongly promoting (as outlined in the 7-point scale of interactions in Fig. 6A) and based on the question "if progress is made toward Target $A$, how does this influence progress toward Target B?". The data entered in the cross-impact matrix serve as the basis for the subsequent systems analysis.

The target interpretations prepared during the customization stage were used as guidance to inform the assessment of interactions. Results are presented in the next section.

\section{Step 3: Analysis}

In the third step, network analysis methods are used to identify more complex patterns of interaction. This includes second-order (or indirect) interactions in the identification of critical trade-offs and synergies between targets, as well as identification of thematic clusters of particularly closely interlinked targets. Figure 5 synthesizes the steps followed in each of the cases.

In all cases, a network analysis was carried out by SEI using different open-source software, with the results of

\footnotetext{
$\overline{2}$ The digital version of the tool will be made available online https:// www.sei.org/projects-and-tools/tools/sdg-synergies/\#overview
}

the interactions assessment (i.e., the first-order analysis) as input. This type of analysis shows how progress toward different targets affect not just one other target but the entire system. For example, if Target A has a +2 influence on Target $\mathrm{B}$, but Target $\mathrm{C}$ has $\mathrm{a}-2$ influence on Target $\mathrm{A}$, then progress toward Target $\mathrm{C}$ would reduce Target A's positive influence on Target B. By considering such systemic effects, the second-order analysis may change our understanding of which targets/goals should be seen as the most influential targets compared to the first-order analysis.

\section{Results}

This section first presents results from the Interactions Assessment and Analysis of SDG Synergies in the country applications, ${ }^{3}$ and next, it presents results related to the three sets of mechanisms system boundaries, rules of engagement, and biases.

Figure 6A, B shows results of the interactions assessment in Sri Lanka. In Mongolia and Colombia, the analysis focused on a short time frame. Scores were based on present conditions, for instance in terms of policy and the kind of solutions (e.g., technologies or budgets) available today. In Sri Lanka, the scoring of interactions did not specify a particular time-period, but was open to both short- and longterm developments.

In Colombia, the network analysis was used to verify the list of priority SDG targets identified in the scoring exercise (workshop). In addition, clusters of targets were identified where the interactions within the clusters were strong and positive and leaving all negative interactions between the clusters. This clustering exercise allowed for the identification of themes that reinforce each other and helped to maximize benefits to advance SDG implementation. It also helped identify the national and regional actors responsible for the implementation of the themes, which could inform new constellations of collaboration.

In Mongolia, results from the network analysis (Fig. 7) were primarily used for capacity building purposes. The intervention included a short online module and written guidance. Staff from the National Development Agency (NDA) with the right background were able to pick up on the methodology and subsequently apply it beyond the intervention.

In Sri Lanka, the information generated on the systemic influence of targets, both synergies and trade-offs, aimed to inform priority setting across the set of included targets. In particular, the analysis identified accelerators targets in

\footnotetext{
${ }^{3}$ Detailed descriptions of results can be found in Barquet et al., (2019) for Mongolia, and Järnberg et al., (2021) for Sri Lanka.
} 
Fig. 6 A Scale of Synergies. Negative value represent trade-offs and positive values are synergies. B Cross-impact matrix for a national level SDG Synergies analysis in Sri Lanka. The matrix should be read starting from the $X$ axis. In the example above, progress on target 2.3 (agricultural productivity) has been scored as having a moderately restricting effect

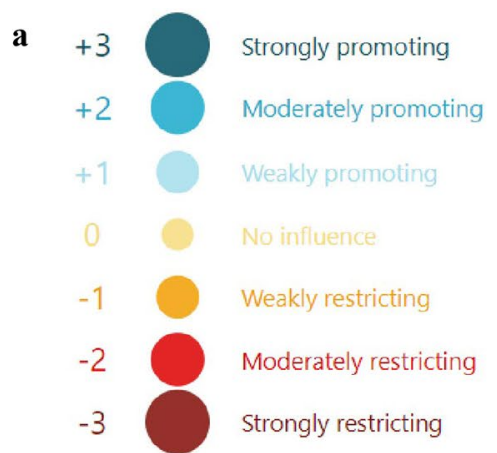

b

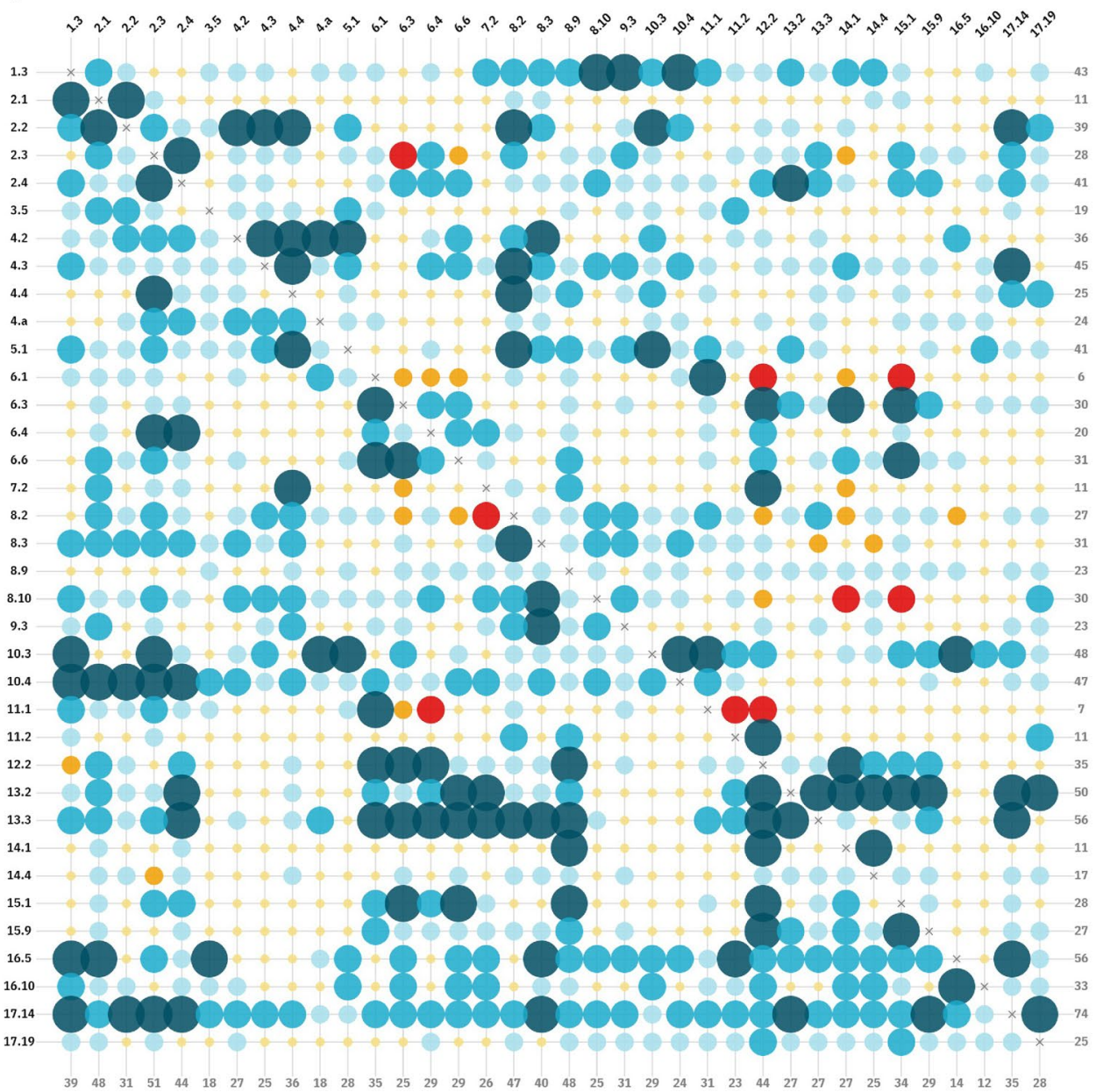

which progress will have a large promoting influence on many other targets. The network in Sri Lanka was very dense (i.e., highly interlinked) and the cluster analysis therefore showed inconclusive results.

\section{System boundaries}

\section{Time}

The three country applications of SDG Synergies highlight the difficulty of imagining and deliberating on future scenarios. The guiding question in SDG Synergies- "If progress is made toward Target $A$, how does this influence progress toward Target B"?-opens for a discussion for more radical type of change, but in practice, stakeholders 
Fig. 7 Network analysis in Mongolia highlighting clusters of targets that promote each other. Targets within the cluster can produce win-win outcomes. Clusters that are closer to each other have a stronger promoting effect. Clusters can provide guidance to governments on alternative ways of organizing their work to increase crosssectoral linkages

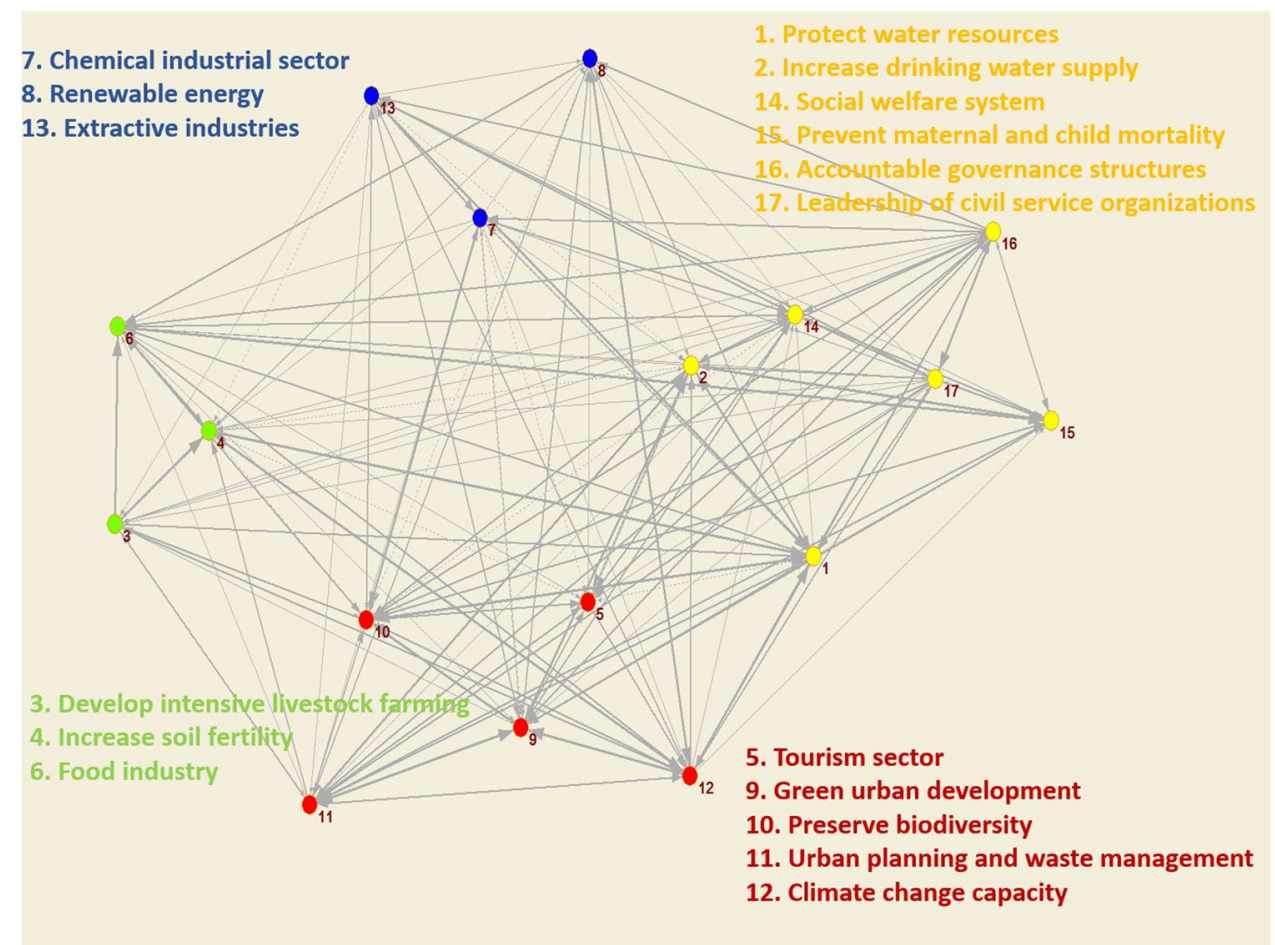

had difficulties assuming different conditions other than their current ones-in terms of policy, economic activity, and factors like social acceptability_and hence imagining more transformative change was challenging. Stakeholders' perception of time is reflective of complex decisionmaking processes (like Agenda 2030 or climate change), where decisions are taken now, based on current budget lines and political priorities, whereas change is sought sometime in the future. A time perspective is fundamental in decision-making, where greater attention is usually given to people and objectives that are close in terms of time and social distance than more distant ones (Weber 2017).

In all cases, the material (scientific and factual data) prepared for the workshops was intended to support the discussions, but we found that they had limited impact for triggering more radical thinking. Hulme (2009) attributes this to the time scale used in scientific narratives for example about future climate change, which are based on intervals of decades to centuries, while most people make decisions and structure their behavior on more immediate timescales.

For feasibility reasons, an analysis focused on incremental, short-term change may be easier to carry out, since it is less speculative and more specific. However, future applications could consider ways of stimulating creative thinking that goes beyond business-as-usual development to support the transformative ambition of the Agenda. Integrating aspects related to time with other system boundaries (scale and space) in the design of the intervention could provide some boundary conditions necessary to shift the discussion. For example, this could include longer time-horizons for the analysis, exemplifying transformative change, and broadening participation to include the more innovate sectors of society.

\section{Scale}

Besides from the regional workshop in Antioquia, all three cases had a national focus. This was deemed challenging as participants were forced to assume homogenous conditions for the whole country, while regional variations related to landscape, demographic, economic, and cultural conditions were difficult to accommodate into the analysis. However, as participants in all three cases highlighted, there are wide inner-country gaps between geographic areas (urban-rural, north-south, coastal-inland), political and social stability (e.g., post-conflict areas, poverty rates), and economic activity (e.g., regions specialized in mining or agriculture).

Scalar tensions highlight the inadequacy of one-sizefits-all approaches and the importance of localizing Agenda 2030 (Alcamo et al. 2020) to capture local dynamics of, for instance, resource availability and use (Bhaduri et al. 2016). Nilsson et al. (2016) even warn against relying on generalized knowledge on SDG interactions because of how 
these interactions are influenced by differences in geography, governance, and technology. Thus, if future assessments of SDGs are adjusted to better reflect scalar differences, SDG Synergies could potentially contribute with a more nuanced analysis, which centralized decision-making processes otherwise often miss. This is in line with the increasing number of publications highlighting the importance of localizing SDG implementation and monitoring of sustainability (Reed et al. 2006; Fisher and Fukuda-Parr 2019; Sterling et al. 2020).

\section{Space}

The three applications show that the purpose of the intervention defines the level of complexity in the process. The case in Sri Lanka indicates that while a more ambitious intervention could help institutionalize a systems approach from the beginning and at the highest level of government, the stakes in the process could also delay or hinder progress due to opposition. By contrast, the case in Mongolia suggests that a more modest start can help create a safe environment of trial-and-error before upscaling the approach, thereby inducing learning and help build capacity for systems thinking. The regional engagement in Antioquia highlights how policy priorities and perceptions toward synergies and trade-offs in fact differed from those at the national level. For instance, participants mentioned the differences between Antioquia, a region rich in natural resources and with extensive mining and agricultural practices, compared to El Chocó, a region which has suffered from extreme poverty and underdevelopment for most of Colombia's history faced in the rest of the territory. It is therefore not surprising that results at the national level differed from the results in the regional engagement. The case in Colombia highlights the importance of connecting the space of policy to scale to produce more meaningful results that better capture the complexity of territories.

\section{Rules of engagement}

\section{Ownership}

Though the engagement process was carefully designed to foster participation and ensure local ownership of the results, a challenge experienced in all workshops relates to the balance between flexibility of the method and scientific quality of the results. Part of owning the process implied defining the scope and purpose (see "purpose" below) of the intervention. Practically, this meant that while government partners had full ownership of the process (including stakeholder and target selection), the authors retained a certain ownership of the method to ensure that it met scientific requirements. A flexible approach that can be tailored to decision-makers' system boundaries is seen as key for ensuring ownership and legitimacy of results among key stakeholders. However, this flexibility also opens for political interference. There is also a risk of tension between the flexibility of the approach to decision-makers needs and interests, and the scientific credibility of the results, where a balance needs to be struck between stakeholder ownership and scientific integrity. For instance, the process for selecting the targets to include in the analysis (i.e., defining the scope of the analysis) was led by government partners as this issue proved particularly sensitive and was critical for ensuring continued commitment. In one of the cases, target selection became politicized and made the process contentious, complex, and time-consuming.

\section{Representation}

A comparison across the cases highlights the importance of representation for reducing biases (see "Biases"). Overrepresentation of one sector or lack of participation of a group seemed to influence the results of the assessment by skewing them in favor of the most represented group or sector. In all cases, the primary criterion for inclusion of stakeholders was cross-sectoral representation. However, a result of this was an underrepresentation of social groups, such as the Tamils in Sri Lanka and Afro-descendant communities in Colombia. In the case of Mongolia, while the aim was to have a group of key stakeholders representing all sectors affecting and affected by water, government actors within water planning were overrepresented, while, for example, the mining, agriculture, or tourism sectors which are crucial for the economy and are key water users, were missing. The exercise mainly involved stakeholders from the capital city, and in both Mongolia and Colombia, stakeholders argued that capital cities are often used to draw generalizations of a country but bear little resemblance to the challenges across the territory.

Paradoxically, the low or lack of representation of some groups or sectors forced stakeholders to think more actively about how the underrepresented sector or group would resonate. Some participants in Colombia remarked how in the absence of an "expert" within a certain topic in their working groups, they had to represent the perspective of a particular target, many times external to their own field of work. This allowed them to consider impacts of their work upon other sectors in ways that they had not considered previously.

\section{Purpose}

Part of the purpose implies managing expectations regarding the results of SDG Synergies. For example, methodologically, the network analysis is one tool to unveil the web of connections across targets, which would otherwise be too 
complex to analyze. However, the network analysis uses the results of the interactions assessment as input, and thus, it is essential that the process of scoring is deemed reliable by the participants. Thereafter, through the results of the network, it is possible to identify patterns, clusters of interacting targets, and other network effects. Understanding such systemic impacts can help in prioritization and sequencing of action to mitigate negative interactions. However, the expectation in all the cases was that the network analysis would provide the final and more rigorous results in comparison to the interactions assessments. However, the purpose of SDG Synergies is of enabling a process for actors to inform decisions through systemic thinking - and hence a combination of the functionalist and postmodern approaches (Renn and Schweizer 2009). SDG Synergies will not provide an optimal solution (i.e., the neoliberal approach) nor seek to obtain consensus (the deliberative approach).

The advantages from using SDG Synergies are best coined by one of the stakeholder in Sri Lanka who explained that "we often think about how one target influences others, but not both directions, and not assigning a value and direction, and not in a systematic way" (workshop participant, January 2019). In Mongolia, a key informant from NDA explained that "it is interesting to see how everyone has now started to see their own sectors from the perspective of other sectors for medium and long-term policies. It also reveals the lack of understanding of the complex and interdependent nature of the SDGs before the application of SDG Synergies" (Interview key informant NDA, December 2019).

Future engagements should therefore clarify the purpose and devise a process for interpreting results which includes linking results back to the system boundaries, and specifically to the space of policy in question.

\section{Biases}

\section{Confirmation biases}

During the interactions' assessment, four types of confirmation biases were identified:

1. Assuming the same score or impact for both directions of the interactions (i.e., $\mathrm{A} \rightarrow \mathrm{B}$ and $\mathrm{B} \rightarrow \mathrm{A}$ ). For example, increasing renewable energy would have the same impact upon preserving landscapes and biodiversity, as preserving landscapes and biodiversity would have upon renewable energy provision.

2. Tendency to overvalue loose or far-fetched linkages, and to assign overly positive values either toward "their" sector, or to the sectors that most significantly contribute to the economy.

3. Targets for governance, budgets, and strong institutions, are often perceived as indivisible from all other targets.
A problem with this is that governance is used as a black box for explaining all system failures. As a result, the total score for targets on governance and strong institutions had the most positive synergies to and from the rest of the system. This raises the question of whether governance aspects should be excluded from these types of analyses altogether, given their indivisibility with the rest of the Agenda.

4. Searching for indirect linkages between targets as there was no clear boundary between a direct and an indirect synergy.

Despite these shortcomings, the experience of mainstreaming and institutionalizing SDG Synergies in Mongolia indicates that the approach might be able to reduce sectoral confirmation biases to a certain extent, as all sectors are now expected to screen through drafted policies and assess policy interactions before they are legislated using the same approach, explained by the informant.

\section{Participation bias}

Stakeholder maps are one way of preventing biases in participation (Barquet et al. Forthcoming). Though none of the cases carried out a rigorous mapping beforehand, the criteria outlined for identifying participants provided some guidance. Accordingly, a mix in hierarchies (e.g., technical staff and decision-makers) was for the most part obtained; however, dealing with these hierarchies was challenging and it is unclear whether mixing hierarchies is equally fruitful across all cultures. For example, in at least one of the cases, technical staff did not seem comfortable to participate to the same extent as their peers in higher positions. In two of the cases, high-level representatives eventually dropped out of the workshops, something which highlights the need to find the 'right' level of hierarchy to ensure commitment. Future applications should therefore reconsider biases in participation as something that might be beneficial depending on the purpose of the intervention.

\section{Scope for institutionalization}

Institutionalization of systemic thinking into decisionmaking, and of SDG Synergies in particular, is beyond the scope of single applications. However, the experience in Mongolia indicates that there are opportunities to achieve this, for example, by focusing on national policies instead of SDG targets. It could also be about exploring vertical policy coherence (international, national, regional, and local governance) instead of horizontal coherence (across sectors or ministries), for example, by assessing SDGs against national development goals. Or it could also be used to 
assess synergies and trade-offs between different agendas; for example, Agenda 2030 against Nationally Determined Contributions.

In Mongolia, which was the earliest application of SDG Synergies, institutionalization resulted from the process that began in 2017 on integrated water resources and evolved to become the government's tool for policy coherence. Two years following the collaboration between SEI, UNDP, and the National Development Agency, the Mongolian government adapted and mainstreamed the application of SDG Synergies across sectors. In 2019, the approach was accepted into Mongolian legislation as the government's main tool for aligning national development policies with sustainable development goals. This was done by adopting a government resolution to amend the procedure for drafting development policy documents. The revised legislation integrates an adapted version of SDG Synergies, which besides from capturing vertical policy coherence (harmonization between Agenda 2030 and national development plans), also captures horizontal synergies (across sectors in the medium and long term). According to the legislation, these components of SDG Synergies are to be used like a manual for formulating policy and planning in all sectors.

The adoption of SDG Synergies in Mongolia has led to four results. First, the government has through NDA, held training sessions across sectors to support the implementation of Agenda 2030. The trainings have enhanced stakeholders understanding of cross-sectoral complexities of the SDGs and development challenges overall. "In the sectors where it has been applied, the process for organizing, presenting and facilitating meetings for drafting sectoral policy goals and objectives went from being top-down to a consensus-based approach by using SDG Synergies", explains the informant from Mongolia.

Second, the institutionalization of a tool like SDG Synergies has been "instrumental in establishing a foundation for effective implementation of the Agenda 2030" in Mongolia (National Voluntary Review 2019). SDG Synergies has supported consensus-building in policy-making and planning processes, and multi-stakeholder consultations at early stages of policy planning have increased generally by the government. "Legislating SDG Synergies as the common approach for ensuring a "whole government" and "whole society" approach has helped us build consensus in policymaking and planning processes. Today, people are talking integration, coherence, and SDGs. Before 2017, the word coherence was hardly popular", explains the informant.

Third, the adoption of SDG Synergies has helped strengthen the institutional role of NDA. From its inception, the agency has been tasked with leading SDG implementation, but today, the informant explains, there is greater willingness and capacity to use this mandate for the purpose of advancing sustainable development agendas. For example, in another application of SDG Synergies, the agency summoned over 100 stakeholders from 17 sectors to identify leverage points for SDG implementation. The outcomes of this process were used to structure and frame Mongolia's Voluntary National Review (VNR) of SDG progress, presented at the High-Level Political Forum in July 2019. According to the informant, Mongolia's VNR was recognized as a good practice example, for its introduction of systems thinking. On top of that, the agency's “ability to cut across sectors and siloed ministries was very well received by the government".

Fourth, there is now a mandatory review mechanism in the early stages of policy formulation for identifying policy synergies and conflict across sectors as well as between sectoral policy and long-term national policies like the 2030 Agenda or the Mongolia Sustainable Development Vision 2030. Mainstreaming Mongolia's version of SDG Synergies when national policies and programs are being developed by line ministries has forced each ministry to reflect about effects beyond their own area of responsibility and to work together with stakeholders in other sectors, explains the informant.

\section{Discussion and conclusions}

The indivisible nature of Agenda 2030 places demands on understanding — and acting upon - synergies and trade-offs between policy areas (Nilsson et al. 2018). This takes place in contexts characterized by subjectivity, where personal knowledge and biases, rather than scientific evidence, might be stronger determinants for decisions (Bell et al. 1999). Despite this, there continues to be a remarkable lack of integration of behavioral and contextual mechanisms in decision models.

Through the application of the SDG Synergies approach in Sri Lanka, Mongolia, and Colombia, this paper identified three sets of mechanisms for learning and capacity building related to system boundaries, rules of engagement, and biases.

\section{System boundaries}

All three cases generated time- and space-specific knowledge which served as a basis to develop policy recommendations at national or regional levels. Tailoring the knowledge by aligning the system boundaries of the data with the system boundaries of the decision-makers increases its salience, which enhances the chances of it being used in practice. A difference between the cases is that the Mongolian government had previously carried out the process of harmonizing SDG targets with national development 
goals, and therefore, the selection of targets in this case was done at the level of national development goals (rather than SDG targets). Another difference is the two-scale approach taken in Colombia which led to divergent results between the national and regional-level assessments. The contextualization in both Mongolia and Colombia were important for increasing the relevance of the discussions to the context and a confirmation that the more localized the knowledge is, the higher its value in supporting decision-making (Alcamo et al. 2020). It is clear from our cases that SDG interactions are indeed very contextual, which makes the case for highly context-specific knowledge to support SDG decision-making and illustrates the limited relevance of exploring generic interactions, for instance at global levels. Thus, regional, and even more localized, analyses are required to inform the national level. A recommendation is that studies seeking to support systemic decision-making for sustainable development should align the system boundaries of the study with the system boundaries of decision-makers.

\section{Rules of engagement}

In all cases, strong involvement, and ownership from decision-makers, along with an explicit purpose to use the knowledge for policy-making, ensured that the knowledge produced was perceived as legitimate by key stakeholders. For instance, a very thorough, government-led process for selecting the targets was critical for ensuring continued ownership and legitimacy of the results. Acceptance of results can in turn be crucial for creating support for policy or budget reforms, improving policy coherence, and increasing cross-sectoral collaboration in processes informed by results from the SDG Synergies analysis (Barquet et al. 2019). It is important to note that in all cases, there seemed to be higher trust in results that emerged from the more quantitative assessment (i.e., the network analysis)_for example, an expectation that these results would indicate a path of action-in comparison to the qualitative assessment from the interactions. Future applications should therefore manage expectations and ensure understanding for how results connect back to policy.

\section{Biases}

One of the biases that was most challenging to address was the tendency of overly positive scoring of interactions, which reflects an unwillingness to acknowledge trade-offs. This behavior appeared to be driven by an overly positive view of the contribution of one's "own" sector, and a political interest of boosting the importance of one's own sector to motivate increased political priority and resource allocation. To some extent, it may also be a cultural factor where, in certain contexts, it may be perceived as more appropriate to focus on positive aspects than negative ones (KoopmannHolm and Tsai 2014). However, identifying trade-offs is crucial for designing appropriate mitigation or other actions. For example, economic development is likely to have a negative impact on many environmental targets. This does not mean that the target should be dismissed or down prioritized. Rather, it means that actions to mitigate negative impacts will be necessary. Future applications of SDG Synergies and similar methodologies should therefore focus on clarifying that trade-offs are not unavoidable, but can be overcome or compensated for through careful implementation.

A participatory approach that involves a broad set of stakeholders and addresses common participation biases in a mindful way can also ensure a diverse, and hence more systemic, knowledge base. Representation of multiple sectors was an important starting point for ensuring diversity, but it is clear from our cases that addressing participation biases was equally important. While government agencies have a strong convening power, which is needed to summon key stakeholders, a challenge is to ensure balance in representation across sectors, genders, social groups, and geographic spread. Finally, while the workshops had a specific aim to obtain participation from different levels of decision-making, the three country applications indicate that hierarchical differences could jeopardize equality in participation, which seems to be a more important determinant for knowledge uptake and capacity building than diversity in representation.

\section{SDG Synergies as a mechanism for building knowledge and capacity}

Increased systems' thinking capacity - that is, the capacity to consider systemic effects of policies and actions-is necessary for translating the systemic knowledge on SDG interactions into practice. For all three cases, there are capacity building outcomes from the process itself. Inclusion of targets and stakeholders from across sectors and a systematic method to consider interactions appear to have pushed participants to think more systemically about how their sector affects and is affected by other sectors.

SDG Synergies captures the knowledge of stakeholders engaged in deliberative processes. Data and scientific analysis become inputs, not unassailable authorities, meaning that the outcomes reflect stakeholders' day-to-day realities. Furthermore, SDG Synergies can be used to examine multiple policy spaces, for example not only vertical coherencebetween global, national, and local strategies - but also how situations and interactions change over time. And lastly, a main characteristic of the approach is the ability to start 
conversations and deepen understanding between sectors, turning competition into cooperation.

Despite its advantages, future applications of SDG Synergies and similar approaches should consider: adopting a more place-sensitive approach that better captures incountry differences; addressing confirmation biases toward trade-offs; exploring methodologies that allow stakeholders to imagine transformative, and not only incremental, change; and obtaining a balance between the flexibility of the method-which ensures legitimacy and salience-with scientific integrity—which ensures credibility.

Acknowledgements We acknowledge and thank our partners in the case studies: The National Designated Authority in Mongolia, UNDP Mongolia, UNDP Asia, UNDP Sri Lanka, the Ministry of Sustainable Development in Sri Lanka, Centre for Poverty Analysis in Sri Lanka, the National Planning Department and the Ministry of Environment and Sustainable Development in Colombia, UN Environment Programme Office for Latin America and the Caribbean, and UN Environment Programme Colombia. We thank the three anonymous reviewers for their constructive feedback.

Funding SEI core funds provided by the Swedish International Development Cooperation Agency, UNDP Asia/Mongolia, UN Environment Programme Office for Latin America, and the Caribbean.

Open Access This article is licensed under a Creative Commons Attribution 4.0 International License, which permits use, sharing, adaptation, distribution and reproduction in any medium or format, as long as you give appropriate credit to the original author(s) and the source, provide a link to the Creative Commons licence, and indicate if changes were made. The images or other third party material in this article are included in the article's Creative Commons licence, unless indicated otherwise in a credit line to the material. If material is not included in the article's Creative Commons licence and your intended use is not permitted by statutory regulation or exceeds the permitted use, you will need to obtain permission directly from the copyright holder. To view a copy of this licence, visit http://creativecommons.org/licenses/by/4.0/.

\section{References}

Ajzen I (1991) The theory of planned behavior. Organ Behav Hum Decis Process 50:179-211. https://doi.org/10.1016/0749-5978(91) 90020-T

Alcamo J, Thompson J, Alexander A et al (2020) Analysing interactions among the sustainable development goals: findings and emerging issues from local and global studies. Sustain Sci 15:1561-1572. https://doi.org/10.1007/s11625-020-00875-x

Armitage D, Berkes F, Dale A et al (2011) Co-management and the co-production of knowledge: learning to adapt in Canada's Arctic. Glob Environ Change 21:995-1004. https://doi.org/10.1016/j. gloenvcha.2011.04.006

Banuri S, Dercon S, Gauri V (2019) Biased policy professionals. World Bank Econ Rev 33:310-327. https://doi.org/10.1093/wber/lhy033

Barbier EB, Burgess JC (2019) Sustainable development goal indicators: analyzing trade-offs and complementarities. World Dev 122:295-305. https://doi.org/10.1016/j.worlddev.2019.05.026
Barquet K, Trimmer C, Sturesson A et al (2019) Piloting the SDG Synergies approach in Mongolia. Stockholm Environment Institute (SEI), Stockholm

Barquet K, Segnestam L, Dickin S (Forthcoming) MapStakes: a tool for mapping, involving and monitoring stakeholders in co-creation processes. Stockholm Environment Institute (SEI), Stockholm

Bell DE, Raiffa H, Tversky A (eds) (1999) Decision making: descriptive, normative, and prescriptive interactions, Nachdr. Cambridge Univ Press, Cambridge

Bennich T, Weitz N, Carlsen H (2020) Deciphering the scientific literature on SDG interactions: a review and reading guide. Sci Total Environ 728:138405. https://doi.org/10.1016/j.scitotenv.2020. 138405

Berg M, Lidskog R (2018) Deliberative democracy meets democratised science: a deliberative systems approach to global environmental governance. Environ Polit 27:1-20. https://doi.org/10.1080/09644 016.2017.1371919

Bhaduri A, Bogardi J, Siddiqi A et al (2016) Achieving sustainable development goals from a water perspective. Front Environ Sci. https://doi.org/10.3389/fenvs.2016.00064

Boyko JA, Lavis JN, Abelson J et al (2012) Deliberative dialogues as a mechanism for knowledge translation and exchange in health systems decision-making. Soc Sci Med 75:1938-1945. https:// doi.org/10.1016/j.socscimed.2012.06.016

Butler R (1995) Time in organizations: its experience, explanations and effects. Organ Stud 16:925-950. https://doi.org/10.1177/ 017084069501600601

Cash D, Clark WC, Alcock F, et al (2003) Salience, credibility, legitimacy and boundaries: linking research, assessment and decision making

Caza BB, Tiedens L, Lee F (2011) Power becomes you: the effects of implicit and explicit power on the self. Organ Behav Hum Decis Process 114:15-24. https://doi.org/10.1016/j.obhdp.2010.09.003

Chambers JM, Wyborn C, Ryan ME et al (2021) Six modes of coproduction for sustainability. Nat Sustain. https://doi.org/10.1038/ s41893-021-00755-x

Cvitanovic C, McDonald J, Hobday AJ (2016) From science to action: principles for undertaking environmental research that enables knowledge exchange and evidence-based decision-making. J Environ Manage 183:864-874. https://doi.org/10.1016/j.jenvm an.2016.09.038

Dryzek JS (2001) Legitimacy and economy in deliberative democracy. Polit Theory 29:651-669. https://doi.org/10.1177/0090591701 029005003

Engler J-O, Abson DJ, von Wehrden H (2019) Navigating cognition biases in the search of sustainability. Ambio 48:605-618. https:// doi.org/10.1007/s13280-018-1100-5

Fisher A, Fukuda-Parr S (2019) Introduction—data, knowledge, politics and localizing the SDGs. J Hum Dev Capab 20:375-385. https://doi.org/10.1080/19452829.2019.1669144

Gavine A, MacGillivray S, Ross-Davie M et al (2018) Maximising the availability and use of high-quality evidence for policymaking: collaborative, targeted and efficient evidence reviews. Palgrave Commun 4:5. https://doi.org/10.1057/s41599-017-0054-8

George J, Jones GR (2000) The role of time in theory and theory building. J Manag 26:657-684. https://doi.org/10.1016/S01492063(00)00051-9

Halpern JJ, Stern RC (2018) Debating Rationality: Nonrational Aspects of Organizational Decision Making. https://www.degruyter.com/ doi/book/10.7591/9781501725470

Holling CS (ed) (1978) Adaptive environmental assessment and management, Reprint of the 1978 ed. Blackburn Press, Caldwell

Hulme M (2009) Why we disagree about climate change: understanding controversy, inaction and opportunity. Cambridge University Press, UK 
Jasanoff S (ed) (2010) States of knowledge: the co-production of science and social order, transferred to digital print. Routledge, London

Jasanoff S (2012) Science and public reason. Routledge, New York

Kahneman D, Tversky A (1979) Prospect theory: an analysis of decision under risk. Econometrica 47:263. https://doi.org/10.2307/ 1914185

Kato S, Ahern J (2008) 'Learning by doing': adaptive planning as a strategy to address uncertainty in planning. J Environ Plan Manag 51:543-559. https://doi.org/10.1080/09640560802117028

Koopmann-Holm B, Tsai JL (2014) Focusing on the negative: cultural differences in expressions of sympathy. J Pers Soc Psychol 107:1092-1115. https://doi.org/10.1037/a0037684

Lachapelle PR, McCool SF (2005) Exploring the concept of "ownership" in natural resource planning. Soc Nat Resour 18:279-285. https://doi.org/10.1080/08941920590908141

Latour B (1983) Give Me a Laboratory and I will Raise the World. Sage Publ

Lefebvre H (1991) The production of space, translated by Donald Nicholason-Smith. Blackwell Publishing Ltd, Oxford

Lusseau D, Mancini F (2019) Income-based variation in sustainable development goal interaction networks. Nat Sustain 2:242-247. https://doi.org/10.1038/s41893-019-0231-4

Massey DB (2005) For space. SAGE, London, Thousand Oaks, Calif

Mercier H, Landemore H (2012) Reasoning is for arguing: understanding the successes and failures of deliberation: reasoning is for arguing. Polit Psychol 33:243-258. https://doi.org/10.1111/j. 1467-9221.2012.00873.x

Moallemi EA, Zare F, Reed PM et al (2020) Structuring and evaluating decision support processes to enhance the robustness of complex human-natural systems. Environ Model Softw 123:104551. https://doi.org/10.1016/j.envsoft.2019.104551

National Voluntary Review (2019) Mongolia. https://sustainabledeve lopment.un.org/memberstates/mongolia. Accessed 10 Apr 2021

Ney S, Verweij M (2014) Exploring the contributions of cultural theory for improving public deliberation about complex policy problems: cultural theory and complex policy problems. Policy Stud J 42:620-643. https://doi.org/10.1111/psj.12078

Nilsson M, Griggs D, Visbeck M (2016) Policy: map the interactions between sustainable development goals. Nat News 534:320. https://doi.org/10.1038/534320a

Nilsson M, Chisholm E, Griggs D et al (2018) Mapping interactions between the sustainable development goals: lessons learned and ways forward. Sustain Sci 13:1489-1503. https://doi.org/10.1007/ s11625-018-0604-z

Nilsson M, Griggs D, Visbeck M et al (2017) Introduction: A framework for understanding sustainable development goal interactions. A guide to SDG interactions: from science to implementation. International Council for Science (ICSU), Paris

Parkinson J (2003) Legitimacy problems in deliberative democracy. Polit Stud 51:180-196. https://doi.org/10.1111/1467-9248.00419

Parsons W (2004) Not just steering but weaving: relevant knowledge and the craft of building policy capacity and coherence. Aust $\mathbf{J}$
Public Adm 63:43-57. https://doi.org/10.1111/j.1467-8500.2004. 00358.x

Peck J (2011) Geographies of policy: from transfer-diffusion to mobility-mutation. Prog Hum Geogr 35:773-797. https://doi.org/10. $1177 / 0309132510394010$

Pierce J, Neeley G, Budziak J (2008) Can deliberative democracy work in hierarchical organizations? J Pub Delib 4(1). https://doi.org/ $10.16997 /$ jdd.67

Reed MS, Fraser EDG, Dougill AJ (2006) An adaptive learning process for developing and applying sustainability indicators with local communities. Ecol Econ 59:406-418. https://doi.org/10.1016/j. ecolecon.2005.11.008

Reed MS, Vella S, Challies E et al (2018) A theory of participation: what makes stakeholder and public engagement in environmental management work?: A theory of participation. Restor Ecol 26:S7S17. https://doi.org/10.1111/rec.12541

Renn O, Schweizer P-J (2009) Inclusive risk governance: concepts and application to environmental policy making. Environ Policy Gov 19:174-185. https://doi.org/10.1002/eet.507

Sarkki S, Niemelä J, Tinch R et al (2014) Balancing credibility, relevance and legitimacy: a critical assessment of trade-offs in science-policy interfaces. Sci Public Policy 41:194-206. https://doi. org/10.1093/scipol/sct046

Schlüter M, Baeza A, Dressler G et al (2017) A framework for mapping and comparing behavioural theories in models of social-ecological systems. Ecol Econ 131:21-35. https://doi.org/10.1016/j.ecolecon. 2016.08.008

Sterling EJ, Pascua P, Sigouin A et al (2020) Creating a space for place and multidimensional well-being: lessons learned from localizing the SDGs. Sustain Sci 15:1129-1147. https://doi.org/10.1007/ s11625-020-00822-w

Van Lieshout M, Dewulf A, Aarts N, Termeer C (2017) The power to frame the scale? Analysing scalar politics over, in and of a deliberative governance process. J Environ Policy Plan 19:550-573. https://doi.org/10.1080/1523908X.2014.936581

Vieider FM, Vis B (2019) Prospect theory and political decision making. Oxford research encyclopedia of politics. Oxford University Press

Weber EU (2017) Breaking cognitive barriers to a sustainable future. Nat Hum Behav 1:0013. https://doi.org/10.1038/s41562-016-0013

Weitz N, Carlsen H, Nilsson M, Skånberg K (2018) Towards systemic and contextual priority setting for implementing the 2030 Agenda. Sustain Sci 13:531-548. https://doi.org/10.1007/ s11625-017-0470-0

Wondolleck JM, Yaffee SL (2000) Making collaboration work: lessons from innovation in natural resource management. Island Press, Washington, D.C.

Publisher's Note Springer Nature remains neutral with regard to jurisdictional claims in published maps and institutional affiliations. 